\title{
CLINICO-PATHOLOGICAL EVALUATION OF PATIENTS WITH ABNORMAL UTERINE BLEEDING
}

\author{
Rabiah Anwar, Nighat Jamal, Sobia Anwar \\ Pakistan Naval Ship, Shifa Hospital Karachi Pakistan
}

\begin{abstract}
Objective: To evaluate clinical spectrum in women of different age groups presenting with menstrual irregularities without any organic pelvic pathology and to correlate clinical and pathological aspects in these women.

Study Design: Cross sectional analytical study.

Place and Duration of Study: Department of Gynecology and Obstetrics, Pakistan Naval Ship (PNS) Shifa Hospital, Karachi from Feb 2018 to Jan 2019.

Methodology: Complete history, clinical examination, laboratory investigations, pelvic scan and endometrial biopsy of patients were done to diagnose abnormal uterine bleeding without organic (structural) pathology. Evaluation of clinical spectrum of menstrual irregularities in different age groups and histopathology of their endometrial samples was done.

Results: A total of 184 cases were included. Mean age of patients presented with abnormal uterine bleeding was $38.49 \pm 9.158$. It was most common in the age group $41-50$ years $(41.84 \%)$ followed by $31-40$ years $(29.34 \%)$. Majority of them were multipara $146(79.34 \%)$. The most common presentation was heavy menstrual bleeding $(50.54 \%)$ followed by irregular menstrual bleeding $(17.93 \%)$. Histopathology of endometrium revealed proliferative $(41.30 \%)$ followed by hyperplastic $(27.71 \%)$ and secretory $(21.19 \%)$ pattern. $3.26 \%$ had atrophic endometrium and $1.63 \%$ cases had endometrial carcinoma.

Conclusion: In conclusion, 41-50 year age group was mostly affected by abnormal uterine bleeding. Their menstrual pattern was heavy, irregular, frequent and prolonged. Proliferative and hyperplastic pattern of endometrium was observed in these patients.
\end{abstract}

Keywords: Endometrium, Histopathology, Menstrual disturbances.

This is an Open Access article distributed under the terms of the Creative Commons Attribution License (https://creativecommons.org/licenses/by-nc/4.0/), which permits unrestricted use, distribution, and reproduction in any medium, provided the original work is properly cited.

\section{INTRODUCTION}

One of the most common gynecological complaints presented to gynecologist in outdoor patient department is abnormal uterine bleeding (AUB) ${ }^{1}$. Women of reproductive age normally have menstrual flow every 24-38 days. It occurs at regular interval with variation of 7-9 days across cycles. Normal duration of menstrual bleed is 4.5-8 days and about 5-80cc of blood loss occur during one menstrual flow ${ }^{2}$. Abnormal uterine bleeding can be frequent ( $<24$ days), infrequent ( $>38$ days), prologed ( $>8$ days), irregular ( shortest to longest cycle variation: $\geq 8-10$ days) $)^{2,3}$. Clinically, excessive blood loss is defined as a volume that interferes with the women's physical, emotional, social, and/or material quality of life ${ }^{4}$. Bleeding between 2 menstrual cycles is called inter-menstrual bleeding 5 .

AUB can be due to sructural/organic or non stuctural pathologies. "Structural" lesions can be imaged by ultrasonography and/or defined histopathologically (polyp, adenomyosis, leiomyomas and malignancy or atypical endometrial hyperlasia; PALM). Whereas non structural" cannot be imaged. With detailed

Correspondence: Dr Rabiah Anwar, Classified Gynaceologist, Pakistan Naval Ship, Shifa Karachi Pakistan

Received: 31 May 2020; revised received: 21 Aug 2020; accepted: 04 Sep 2020 history, proper physical examination and sometimes supported by laboratory investigations, we can find the nonstructural cause of abnormal uterine bleeding (coagulopathies, ovulatory disorders, primary endometrial disorders, iatrogenic and not otherwise classified; COEIN) ${ }^{6}$. AUB in absence of organic lesion of genital tract can occur at any time during life span of a woman from menarche and occasionally even after the menopause in ovulatory and anovulatory cycles ${ }^{7}$. Its management is not complete without tissue diagnosis especially in peri and post-menopause ${ }^{8}$.

It has been observed that about one third of gynecological consultations are due to AUB symptoms. However, only half of affected women seek consultation. Out of which only fifty percent are satisfied after their hospital visit 9 . Evidence also shows that chronic AUB is associated with $30 \%$ reduction in work productivity ${ }^{10}$. This is an important factor of absence from work for working women. It equally affects the home environment for house wives as well. Local data in this regard is scarce as this problem has not been addressed well. Our study will help in better understanding of AUB, its ways of presentation and its histopathological finding. So we can handle this problem with more robust approach and patients can get satisfactory 
treatment. Furthermore, this will aid to research in our country.

\section{METHODOLOGY}

This analytic study was conducted in department of Gynae/Obstetics, Pakistan Naval Ship (PNS) Shifa Karachi, from February 2018 to January 2019. The study was approved by the ethics committee of the hospital (ERC/2020/Gynae/12). Informed consent was obtained from all the participants and confidentiality was maintained.

Complete history was taken from patients presented with abnormal uterine bleeding. History included age, parity, socioeconomic status, age of menarche, pattern of menstrual irregularity (type, amount and duration of blood loss), associated pain, bleeding from any other site, history of hormonal treatment and any medical issue. Abdominal and pelvic examination was done to rule out clinical pathology. Cervical smear was taken. Pelvic scan from our radiology department was done to rule out organic pathology. Our setup provides free treatment and investigations for the entitled patients. Women with organic lesions such as tumor, fibroid, polyp, adenomyosis, medical problems such as cirrhosis and thyroid disorders were excluded. Adolescent/teen age group and unmarried ladies were also excluded as endometrial sample could not be taken from them. Only women having menstrual irregularities without organic lesions and with no co morbid (such as thyroid disorders and cirrhosis) were included.

We studied 184 cases of abnormal uterine bleeding. Sample size was calculated using WHO sample size calculator. Assuming 12\% frequency of abnormal uterine bleeding among women ${ }^{11}$, minimum sample size of 161 was calculated to provide study $80 \%$ power in assessing clinical and pathological aspects among

Pipelle, preserved in 10\% formaline and sent for histopathological evaluation to pathology department of PNS Shifa Karachi. Patients who were bleeding were prescribed non hormonal treatment till the procedure. Evaluation of spectrum of clinical pre-sentation and endometrial histopathological findings was done among women of different age groups.

Data was analyzed using SPSS19. Mean \pm SD were calculated for quantitative variables. Frequency and percentage were calculated for qualitative variables.

\section{RESULTS}

The patients presenting with menstrual irregularities had age ranging from 21-70 years with mean age $38.49 \pm 9.158$. We obtained highest number of cases i.e. 77 out of $184(41.84 \%)$ in $41-50$ years of age, $54(29.34 \%)$ in $31-40$ years of age, $32(17.39 \%)$ in $21-30$ years age, $19(10.32 \%)$ between 51-60 years while lowest being $2(1.086 \%)$ between $61-70$ years.

We observed that as compared to nulliparous women, AUB was common in parous women. Out of 184 cases, $146(79.34 \%)$ were multipara, 31 (16.84\%) were primipara and $7(3.86 \%)$ were nullipara. Our analysis revealed that $95(51.63 \%)$ cases of AUB were of middle socioeconomic group, 67 (36.41\%) of low and $22(11.95 \%)$ of higher socioeconomic status.

Heavy menstrual bleeding (HMB) (excessive menstrual blood loss that interferes with the women's physical, emotional, social and material quality of life and can occur alone or in combinations with other symptoms) was the most common menstrual disorder in women presenting with AUB. Ninety three cases (50.54\%) were of $\mathrm{HMB}$, followed by $33(17.93 \%)$ cases of irregular menstrual bleeding (variation of $>20$ days in individual cycle lengths over a period of one year). Frequent menstrual bleeding (more than four men-

Table-I: Clinical presentations of menstrual irregularities in different age groups.

\begin{tabular}{l|c|c|c|c|c}
\hline Menstrual Pattern & $\begin{array}{c}\mathbf{2 1 - 3 0} \text { years } \\
\mathbf{n}(\mathbf{0})\end{array}$ & $\begin{array}{c}\mathbf{3 1 - 4 0} \text { years } \\
\mathbf{n}(\mathbf{6})\end{array}$ & $\begin{array}{c}\mathbf{4 1 - 5 0} \text { years } \\
\mathbf{n}(\mathbf{6})\end{array}$ & $\begin{array}{c}\mathbf{5 1 - 6 0} \text { years } \\
\mathbf{n}(\mathbf{6})\end{array}$ & $\begin{array}{c}\mathbf{6 1 - 7 0} \text { years } \\
\mathbf{n}(\mathbf{0})\end{array}$ \\
\hline Heavy Menstrual Bleeding & $23(12.5 \%)$ & $34(18.47 \%)$ & $33(17.93 \%)$ & $3(1.63 \%)$ & - \\
\hline Irregular Menstrual Bleeding & - & $7(3.80 \%)$ & $15(8.28)$ & $9(4.89 \%)$ & $2(1.08 \%)$ \\
\hline prolonged Menstrual Bleeding & $4(2.17 \%)$ & - & $11(5.97 \%)$ & - & - \\
\hline Frequent Menstrual Bleeding & - & $3(1.63 \%)$ & $7(3.80 \%)$ & $6(3.26 \%)$ & - \\
\hline Heavy \& Prolonged Menstrual Bleeding & $2(1.08 \%)$ & $5(2.71 \%)$ & $3(1.63 \%)$ & - & - \\
\hline Infrequent Menstrual Bleeding & - & $3(1.63 \%)$ & $8(4.34 \%)$ & $1(0.54 \%)$ & - \\
\hline Shortened Menstrual Bleeding & $3(1.63 \%)$ & $2(1.08 \%)$ & - & - & - \\
\hline Total & $32(17.39 \%)$ & $54(29.34 \%)$ & $77(41.84 \%)$ & $19(10.32 \%)$ & $2(1.08 \%)$ \\
\hline
\end{tabular}

women of different age groups presenting with menstrual irregularities without any organic pelvic pathology. Endometrial sample of patients was taken by strual episodes in a 90 day period) was observed in 16 patients $(8.69 \%)$. Prolonged menstrual bleeding (periods exceeding 8 days in duration on a regular basis) 
was seen in 15 women $(8.15 \%)$. Infrequent menstrual bleeding (one or two menstrual episodes in a 90-day period) in 12 cases $(6.52 \%)$, heavy and prolonged menstrual bleeding in 10 cases $(5.43 \%)$ and shortened menstrual bleeding (bleeding of no longer than 2 days) was observed in 5 cases $(2.71 \%)$.

In all age groups, HMB was prevailing. In 41-50 years of age group, heavy, prolonged, frequent and irregular menstrual bleeding pattern was observed as shown in table-I.

Table-II: Histopathological findings of endometrial sample.

\begin{tabular}{l|c}
\hline Endometrial Status & Cases, $\mathbf{n}(\%)$ \\
\hline Proliferative & $76(41.30 \%)$ \\
\hline Secretory & $39(21.19 \%)$ \\
\hline Atrophic & $6(3.26 \%)$ \\
\hline Hyperplastic & $51(27.71 \%)$ \\
\hline Simple Hyperplasia & $28(15.21 \%)$ \\
\hline Complex & $14(7.60 \%)$ \\
\hline Without Atypia & $6(3.26 \%)$ \\
\hline With Atypia & $3(1.63 \%)$ \\
\hline Irregular Shedding & $6(3.26 \%)$ \\
\hline Product of Conception & $1(0.54 \%)$ \\
\hline Arias stella Reaction & $1(0.54 \%)$ \\
\hline Endometrial Polyp & $1(0.54 \%)$ \\
\hline Endometrial Carcinoma & $3(1.63 \%)$ \\
\hline Total & $184(100 \%)$ \\
\hline
\end{tabular}

As far as histopathological finding of endometrium is concerned, the most common type of endometrium observed was proliferative $(41.30 \%)$ followed by Hyperplastic (27.71\%) and secretory (21.19\%). Malignancy was found in $3(1.63 \%)$ cases as shown in table-II.
This study showed that proliferative endometrium was mostly seen in patient of heavy menstrual bleeding $(17.93 \%)$ and irregular menstrual bleeding $(10.32 \%)$. Hyperplasia $(20.1 \%)$ was observed in cases of $\mathrm{HMB}$, whereas 3 cases diagnosed as having endometrial malignancy were of $\mathrm{HMB}$ and prolonged menstrual bleed as depicted by table-IV.

\section{DISCUSSION}

Abnormal uterine bleeding is one of the significant gynecological problem forcing patients to seek advice from doctor. In our study, we did endometrial sampling by Pipelle. Pipelle is an outdoor patient procedure and is very effective tool of endometrial sampling in low risk patient with abnormal uterine bleeding ${ }^{12}$. Endometrial sampling can be done by Pipelle, Vebra and conventional dilatation and currettage. Now a days hysteroscopically directed biopsy is being preferred. In our study, hysteroscopically directed biopsy was not done due to non-availability of this facility in our setup.

In our study, we observed that maximum no. of cases of AUB i.e. 77 cases (41.84\%) were between 41-50 years. Nayak et al ${ }^{7}$, had similar findings. Whereas Doraiswami et al, reported maximum cases $(33.5 \%)$ in the $5^{\text {th }}$ decade of life ${ }^{13}$. In our study, the higher frequency of AUB was observed in perimenopausal age group. It may be due to overlook of their symptoms during their reproductive life but increase in severity of symptoms and increasing disability with increasing age may have forced them to seek consultation in hospital.

The commonest presenting complaint in our

Table-III: Histological findings in different age groups.

\begin{tabular}{l|c|c|c|c|c}
\hline Endometrial Histology & $\mathbf{2 1 - 3 0}$ year & $\mathbf{3 1 - 4 0}$ year & $\mathbf{4 1 - 5 0}$ year & $\mathbf{5 1 - 6 0}$ year & $\mathbf{6 1 - 7 0}$ year \\
\hline Proliferative & $20(10.8 \%)$ & $22(11.95 \%)$ & $34(18.47 \%)$ & - & - \\
\hline Secretory & $11(5.97 \%)$ & $28(15.21 \%)$ & - & - & $2(1.08 \%)$ \\
\hline Atrophic & - & - & - & $-16 \%)$ & - \\
\hline Hyperplastic Type & - & - & $39(21.19 \%)$ & $12(6.52 \%)$ & - \\
\hline Irregular Shedding & - & $3(1.63 \%)$ & $3(1.63 \%)$ & - & - \\
\hline Arias stella Reaction & - & $1(0.543 \%)$ & - & - & - \\
\hline Endometrial Polyp & - & - & $1(0.543 \%)$ & - & - \\
\hline Product of Conception & $1(0.543 \%)$ & - & - & - & - \\
\hline Endometrial Carcinoma & - & - & - & $2(1.63 \%)$ & - \\
\hline Total & $32(17.39 \%)$ & $54(29.34 \%)$ & $77(41.84 \%)$ & $19(10.32 \%)$ & $2(1.08 \%)$ \\
\hline
\end{tabular}

We observed that in all age group proliferative endometrium was common $(41.30 \%)$ whereas hyperplasic type of endometrium was mostly seen in 41-60 years of age groups. Endometrial carcinoma was detected in 51-60 years of age group as shown in table-III. study was heavy menstrual bleed (50.54\%). HMB was observed in $51.87 \%$ cases by Nayak et al ${ }^{7}$, in $64 \%$ cases by Nair et al ${ }^{14}$, in $38.67 \%$ cases by Palwade ${ }^{15}$, and in $40 \%$ cases by Verma ${ }^{16}$. But Jeffcoate found only in $10 \%$ of cases ${ }^{17}$. 
We observed that $6.52 \%$ of cases had infrequent menstrual bleeding pattern. This is comparable to observation by Sharada 18 (8\%) and AK et al, 7 (6.25\%).
Due to persistent corpus luteum, irregular shedding of endometrium was observed in $3.26 \%$ cases whereas Nayak et al , found in $3.13 \%$ and Nagarjuna et

Table-IV: Histopathological findings in relation to clinical presentation.

\begin{tabular}{l|c|c|c|c|c|c|c}
\hline $\begin{array}{l}\text { Histology of } \\
\text { Endometrium }\end{array}$ & $\begin{array}{c}\text { Heavy } \\
\text { Menstrual } \\
\text { Bleeding }\end{array}$ & $\begin{array}{c}\text { Irregular } \\
\text { Menstrual } \\
\text { Bleeding }\end{array}$ & $\begin{array}{c}\text { Prolonged } \\
\text { Menstrual } \\
\text { Bleeding }\end{array}$ & $\begin{array}{c}\text { Frequent } \\
\text { Menstrual } \\
\text { Bleeding }\end{array}$ & $\begin{array}{c}\text { Heavy and } \\
\text { Prolonged } \\
\text { Menstrual } \\
\text { Bleeding }\end{array}$ & $\begin{array}{c}\text { Infrequent } \\
\text { Menstrual } \\
\text { Bleeding }\end{array}$ & $\begin{array}{c}\text { Shortened } \\
\text { Menstrual } \\
\text { Bleeding }\end{array}$ \\
\hline Proliferative & $33(17.93 \%)$ & $19(10.32 \%)$ & $4(2.17 \%)$ & $5(2.71 \%)$ & $3(1.63 \%)$ & $10(5.4 \%)$ & $2(1.08 \%)$ \\
\hline Secretory & $18(9.78 \%)$ & $8(4.34 \%)$ & $4(2.17 \%)$ & $3(1.63 \%)$ & $3(1.63 \%)$ & - & $3(1.63 \%)$ \\
\hline Atrophic & - & - & - & $6(3.26 \%)$ & - & - & - \\
\hline Hyperplastic & $36(19.56 \%)$ & $4(2.71 \%)$ & $6(3.26 \%)$ & - & $3(1.63 \%)$ & $2(1.08 \%)$ & - \\
\hline Irregular shedding & $3(1.63 \%)$ & - & - & $2(1.08 \%)$ & $1(0.54 \%)$ & - & - \\
\hline $\begin{array}{l}\text { Arias stella } \\
\text { reaction }\end{array}$ & $1(0.54 \%)$ & - & - & - & - & - & - \\
\hline Endometrial polyp & - & $1(0.54 \%)$ & - & - & - & - \\
\hline $\begin{array}{l}\text { Product of } \\
\text { conception }\end{array}$ & - & $1(0.54 \%)$ & - & - & - & - \\
\hline $\begin{array}{l}\text { Endometrial } \\
\text { carcinoma }\end{array}$ & $2(1.08 \%)$ & - & $1(0.54 \%)$ & - & - & - \\
\hline Total & $93(50.54 \%)$ & $33(17.93 \%)$ & $15(8.15 \%)$ & $16(8.69 \%)$ & $10(5.43 \%)$ & $12(6.52 \%)$ & $5(2.71 \%)$ \\
\hline
\end{tabular}

In our study, we found $41.30 \%$ cases of proliferative pattern of endometrium. Nayak et al, has similar findings 7 (41.88\%). Whereas Gazozai et al, 19 (31\%) and Muzaffar et al, $20(25.8 \%)$ found lower incidence of proliferative pattern of endometrium. Bindroo et al, also observed higher number of cases of proliferative endometrium (37.2\%) suggesting that anovulation may be reason of $\mathrm{AUB}^{21}$.

In our study, out of 32 cases belonging to 21-30 years of age group, $20(10.8 \%)$ had proliferative pattern of endometrium. Similar findings were observed by Nayak et $a l^{7}$. HMB was the most common bleeding pattern in this type of endometrium.

We observed $21.19 \%$ of cases of secretory endometrium and most of them were of 31-40 years of age. Our incidence nearly correlates with finding of Nayak et al, $7(21.88 \%)$. Whereas Bolde et al 22 , reported low incidence of $5.97 \%$.

We noticed endometrial hyperplasia in $27.7 \%$ cases whereas Khan et al, observed in $20.5 \%$ cases 23 and Nayak et al, in $27.5 \%$ cases $^{7}$. In patients with endometrial hyperplasia, we found $54.90 \%$ cases with simple hyperplasia whereas AK et al, found $65.9 \%$ of cases with simple hyperplasia without atypia. Majority of them were between 41-50 years of age.

We found atrophic endometrium in $3.26 \%$ of cases whereas Nayak et al, in $2.5 \%$ of cases 7 , Katuwal et $a l$, in $68 \%$ of cases $^{24}$. Atrophic endometrium was observed in cases of more than 50 years of age. al in $6 \%$ cases $^{25}$.

We found endometrial carcinoma in $1.63 \%$ cases whereas Nayak et al, observed $1.25 \%$ cases of endometrial carcinoma ${ }^{7}$. All of them were $>50$ years of age.

Our study was conducted in tertiary care hospital which is not representative of the country. PNS Shifa is a teaching hospital and caters for large number of Armed Forces and civilian personnel. Therefore, it gives insight of picture of women with abnormal uterine bleeding, their bleeding pattern and endometrium histopathology.

\section{CONCLUSION}

In conclusion, 41-50 years ladies were mostly affected by AUB. The most common bleeding pattern in all age groups was heavy menstrual bleeding. Proliferative endometrium was the predominant histopathological type obsereved in our set up. Histopathological evaluation of endometrium seems quite helpful in excluding local causes and making diagnosis of AUB. This eventually is useful in determining the mode of management for patient.

\section{CONFLICT OF INTEREST}

This study has no conflict of interest to be declared by any author.

\section{REFERENCES}

6. Benetti-Pinto CL, Rosa-e-Silva AC, Yela DA, SoaresJúnior JM. Abnormal uterine bleeding. Revista Brasileira de Ginecologia e Obstetrícia 2017; 39(7): 358-68. 
7. Fraser IS, Critchley HO, Munro MG, Broder M. A process designed to lead to international agreement on terminologies and definitions used to describe abnormalities of menstrual bleeding. Fertility and Sterility 2007; 87(3): 466-76.

8. Fraser IS, Critchley HO, Munro MG, Broder M. Can we achieve international agreement on terminologies and definitions used to describe abnormalities of menstrual bleeding?. Human Reproduct 2007; 22(3): 635-43.

9. Lumsden MA. Women's Health: Adopt an evidence-based approach to menorrhagia. Practitioner 2007: 1(1); 26-31.

10. Munro MG, Critchley HO, Fraser IS. Research and clinical management for women with abnormal uterine bleeding in the reproductive years: More than Palm Coein. Bjog An Inter J Obstetr Gynaecol 2017; 124(2): 185-89.

11. Munro MG, Critchley HO, Fraser IS, FIGO menstrual disorders committee, Haththotuwa R, Kriplani A, Bahamondes L, Füchtner C, Tonye R, Archer D, Abbott J. The two FIGO systems for normal and abnormal uterine bleeding symptoms and classification of causes of abnormal uterine bleeding in the reproductive years: 2018 revisions. Inter J Gynecol Obstet 2018; 143(3): 393-408.

12. Nayak AK, Hazra K, Manju KJ. Clinico-pathological evaluation of dysfunctional uterine bleeding. Int J Contemp Med Res 2017; 4(4): 920-24.

13. Kazemijaliseh H, Tehrani FR, Behboudi-Gandevani S, Khalili D, Hosseinpanah F, Azizi F. A population-based study of the prevalence of abnormal uterine bleeding and its related factors among iranian reproductive-age women: an updated data. Archives Iran Med 2017; 20(9): 8-13.

14. Frick KD, Clark MA, Steinwachs DM, Langenberg P, Stovall D, Munro MG, et al. STOP-DUB research group. Financial and quality-of-life burden of dysfunctional uterine bleeding among women agreeing to obtain surgical treatment. Women's Health Issues 2009; 19(1): 70-78.
15. Fraser IS, Mansour D, Breymann C, Hoffman C, Mezzacasa A, Petraglia F. Prevalence of heavy menstrual bleeding and experiences of affected women in a European patient survey. Inter J Gynecol Obstetr 2015; 128(3): 196-200.

16. Abid M, Hashmi AA, Malik B, Haroon S, Faridi N, Edhi MM, et al. Clinical pattern and spectrum of endometrial pathologies in patients with abnormal uterine bleeding in Pakistan: need to adopt a more conservative approach to treatment. BMC Women's Health 2014; 14(1): 1-7.

17. Narice BF, Delaney B. Endometrial sampling in low-risk patients with abnormal uterine bleeding: a systematic review and metasynthesis. BMC Family Practice 2018; 19(1): 135-38.

18. Doraiswami S, Johnson T, Rao S, Rajkumar A, Vijayaraghavan J, Panicker VK. Study of endometrial pathology in abnormal uterine bleeding. J Obstet Gynecol Ind 2011; 61(4): 426-30.

19. Nair R, Mallikarjuna M. Clinical profile of patients with abnormal uterine bleeding at a tertiary care hospital. Int J Reprod Contracept Obstet Gynecol 2015; 4(1): 1753-57.

20. Palwade JM, Borole CS. A study of causes of abnormal uterine bleeding with re classification in the patients at perimenopausal age. Med Pulse Inter Med J 2016; 3(11): 987-91.

21. Verma R. A study on abnormal uterine bleeding in perimenopausal age in rural Bihar. J Med Sci Res 2016; 4(1): 9262-74.

22. Jeffcoate N, Tindall TR. Jeffcoate's principles of gynaecology, $5^{\text {th }}$ ed. London Butterworths 1987: 1(1); 513-31.

23. Sharada MS, Ebinesh A. Clinico-pathological study of endometrium in dysfunctional uterine bleeding: An experience with D \& C specimens. Sch J App Med 2016; 4(6D): 2144-52.

24. Gazozai S, Bugti QA, Siddiqa A. Excessive uterine haemorrhagea histopathological study. Gomal J Med Sci 2004; 2(1): 13-15.

25. Muzaffar M, Akhtar KA, Yasmin S, Rehman M, Iqbal W, Khan MA. Menstrual irregularities with excessive blood loss: a clinicopathological correlation. J Pak Med Assoc 2005; 55(11): 486-89. 